\title{
Leveraging Resist Chemistry Research for Water Purification Membrane Technology
}

\author{
Robert D. Allen, Young-Hye Na, Ratnam Sooriyakumaran, Masaki \\ Fujiwara* and Kazuhiro Yamanaka*
}

\author{
IBM Almaden Research Center, 650 Harry Rd., San Jose, California, USA, \\ *Central Glass assignees at IBM Almaden Research Center, \\ *Central Glass Corporation, Ltd., Chiyoda-ku, Tokyo, 101-10054 (Japan)
}

This paper gives examples of the connection of new research on water purificiation membranes to earlier research on resist chemistry. Two new membrane materials are reported here. The first is a reverse osmosis desalination membrane material based on a new hexafluoro alcohol-modified aromatic polyamide. This polymer is made in a reactive casting operation using interfacial polycondensation. The membrane has intriguing performance with $\mathrm{pH}$-dependent properties. The second membrane presented here is designed to have fouling resistance. We found through the course of this work that the material had intrinsic nanofiltration properties and data is presented that supports this finding. Research experiences in high performance functional materials can accelerate new efforts in other areas of technology, in this case sustainability.

Keywords: membranes, desalination, anti-fouling coatings

\section{Introduction:}

Water is a constrained resource today and will likely become more of a concern in the future as world population growth, industrialization and climate change contribute. A sustainable supply of clean water for human use will require innovation in water purification technology, delivery, and water management [1]. This 'global water crisis' has lead to great interest in improved water purification technologies [2].

IBM has developed a water focus as part of the Smarter Planet technology program. As part of this effort, IBM Research has recently initiated a program, called 'Nanomembrane Research', with the goal of developing new, high performance materials for a variety of water purification applications.
Desalination of sea water through membrane processes, specifically Reverse Osmosis (RO), is growing in importance as it combines relatively low energy with a scalable solution [3]. The operating principle of RO involves pressuring salt water through a dense, semi-permeable membrane. The membrane assembly needs to have adequate mechanical properties to withstand the pressures involved in RO operation (1000 psi) used to both overcome the natural osmotic pressure and get adequate throughput. The preferred solution is to use a thin film composite (TFC) membrane with three or four separate layers stacked, including the top separator layer responsible for the desalination [3]. Improved materials for reverse osmosis (RO) membranes should include more effective salt removal with high flux, ability 
to resist fouling during long term use, and improved chlorine tolerance. Anti-fouling coatings are a very active area of current research [4] and should resist fouling of the membrane surface from organic sources, oil, etc.

Our initial entry into this field was accelerated through experience in resist chemistry research. Two materials approaches are discussed in this paper, the first being a desalination membrane that directly grew out of expertise in HFA (hexafluoroalcohol) chemistry developed for $193 \mathrm{~nm}$ resists [5], the second being a fouling-resistant nanofiltration membrane that grew out of materials we had originally designed for nano-imprint resists [6]. Through this publication, the authors attempt to demonstrate the utility of photopolymer or photoresist research in generating technologies for a more sustainable world.

\section{Experimental}

2.1. Preparation of HFA-containing polyamide $\mathrm{RO}$ membranes

A Polysulfone Ultra-filtration (PSF UF) membrane was treated with UV-Ozone for 40 seconds before being subjected to membrane growth and deposition via interfacial polymerization. The substrate preparation process serves to increase the coverage and subsequently film quality of ionized HFA-diamine monomers which are dissolved in aqueous basic solution. The pre-treated PSF membrane was placed in an aqueous basic solution of $2 \%(\mathrm{w} / \mathrm{v}) 3,3^{\prime}-$ Bis(1-hydroxy-1-trifluoromethyl-2,2,2trifluoroethyl)-4,4'-methylenedianiline (HFA-MDA, from Central Glass, Inc. (Japan)) for 5 min (2 eq. of $\mathrm{NaOH}$ was added to completely dissolve HFA-MDA monomer), and the HFA-MDA soaked support membranes were then rolled with a rubber roller to remove excess solution. The HFA-MDA saturated membrane was then immersed in a solution of $0.5 \%(\mathrm{w} / \mathrm{v})$ trimesoyl chlroride (TMC, from Aldrich) in hexane. After $30 \mathrm{sec}$ of reaction, the resulting membrane was rinsed with an aqueous solution of $0.2 \%(\mathrm{w} / \mathrm{v})$ sodium carbonate and stored in pure water.

2.2. Evaluation of RO performance and chlorine resistance of i-phobe membranes

Membrane performance was evaluated using a crossflow filtration system. The pure water flux was measured at room temperature $\left(25^{\circ} \mathrm{C}\right)$ after the membrane was compressed for 5 hours at 27.6 bar (cross-flow rate $3.8 \mathrm{~L} \mathrm{~min}^{-1}$ ). The salt rejection was performed using an aqueous feed containing $2000 \mathrm{ppm}$ aqueous solution of $\mathrm{NaCl}$ at the same pressure, and the rejection (R) was calculated as follows:

$$
R(\%)=100 \times\left(1-C_{p} / C_{f}\right),
$$

where $C_{p}$ and $C_{f}$ were the salt concentrations of permeate and feed, respectively. The $\mathrm{pH}$ of the feed water was varied from 4 to 10 by using diluted $\mathrm{HCl}$ and $\mathrm{NaOH}$ solutions.

Boron (III) filtration: $75.5 \mathrm{mg}$ of $\mathrm{H}_{3} \mathrm{BO}_{3}$ (B(III)) was dissolved in $100 \mathrm{~mL}$ of pure water, and this solution was added to 4 gallons of water (B(III) concentration: 5 $\mathrm{mg} / \mathrm{L}$ ). Boron rejection was measured with this feed solution by using cross-flow filtration system at 400 psi. $\mathrm{pH}$ of feed solution was adjusted using $1 \mathrm{M} \mathrm{NaOH} .15$ $\mathrm{mL}$ of permeate was collected for each test and boron concentration of permeate samples was analyzed by Inductively Coupled Plasma Mass Spectroscopy (ICPMS).

Arsenate (As(V)) filtration: $4 \mathrm{mg}$ of $\mathrm{Na}_{2} \mathrm{HAsO}_{4}(\mathrm{As}(\mathrm{V}))$ was dissolved in $14 \mathrm{~mL}$ of pure water. $12.5 \mathrm{~mL}$ of this solution was added to 4 gallons of water (this produced an $\mathrm{As}(\mathrm{V})$ ion concentration of approximately $200 \mathrm{microgram} / \mathrm{L}$ ) .8 .8 grams of $\mathrm{NaCl}$ was added to the solution $(10 \mathrm{mM}$ 
$\mathrm{NaCl}, 200$ ug $\mathrm{As}(\mathrm{V}) / \mathrm{L}, 10 \mathrm{mM} \mathrm{NaCl}, \mathrm{pH}=$ 7.3). As(V) rejection was measured with this feed solution by using cross-flow filtration system at $400 \mathrm{psi}$. $\mathrm{pH}$ of feed solution was adjusted using $1 \mathrm{M} \mathrm{NaOH} .15 \mathrm{~mL}$ of permeate was collected for each test and $\mathrm{As}(\mathrm{V})$ concentration of permeate samples was analyzed by ICP-MS.

Arsenite $(\mathrm{As}(\mathrm{III}))$ Filtration: $10 \mathrm{mg}$ of $\mathrm{As}_{2} \mathrm{O}_{3} \quad(\mathrm{As}(\mathrm{III}))$ was dissolved in approximately $10 \mathrm{~mL} \quad 0.2 \mathrm{M} \mathrm{HCl}$ solution under sonication for a couple of hours. $4 \mathrm{~mL}$ of this solution was added to 4 gallons of feed water to get an As(III) concentration of $200 \mathrm{ug} / \mathrm{L}$. Everything else was done exactly the same here as with the $\mathrm{As}(\mathrm{V})$ filtration experiments.

2.3. Preparation of POSS-PEGM antifouling coatings

A PSF support membrane was soaked in the mixed solvents of glycerol and methanol (15\% glycerol) to remove any dust on the top surface and dried in air before coating. A prepolymerization mixture of $5 \mathrm{wt} \%$ methacrylated POSS (cage mixture 8-12, Hybrid Plastics), 95 wt \% of poly(ethylene glycol) methacrylate (PEGM, Mw: 526, Aldrich), and a photoinitiator (CIBA, Darocur 4265, 1 wt \% to the total amount of speed: $2.5 \mathrm{~cm} / \mathrm{s}$ ). To generate higher flux via nanochannel formation inside of the POSSPEGM films, non-crosslinkable polyethylene glycol (PEG, Mw: 400, Aldrich) was added to the prepolymerization mixture with varied amounts and extracted out after UV-curing.

\subsection{Evaluation of anti-fouling efficiency}

Crossflow filtration of oil/water emulsion was carried out to monitor permeate flux of nanochanneled POSS-PEGM coated composite membranes using commercial crossflow filtration system. Oil/water emulsion was prepared by blending vegetable oil/surfactant (weight ratio $=9: 1$ ) with 3L of deionized water (concentration of oil: $1500 \mathrm{ppm}$ ). The crossflow filtration was conducted at $25{ }^{\circ} \mathrm{C}$, and the crossflow rate was $0.35 \mathrm{Gal} / \mathrm{min}$ at $100 \mathrm{psi}$. Permeate flux was recorded by digital balances connected to a computer.

\section{Results and Discussion}

3.1. HFA-containing polyamide $\mathrm{RO}$ membranes (i-phobe membranes) [7]

HFA-containing aromatic polyamide $(i$ phobe) membranes were synthesized by interfacial polymerization on a porous polysulfone (PSF) ultrafiltration (UF)

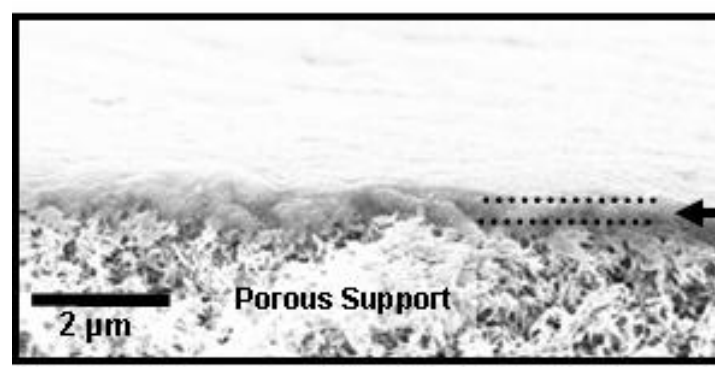

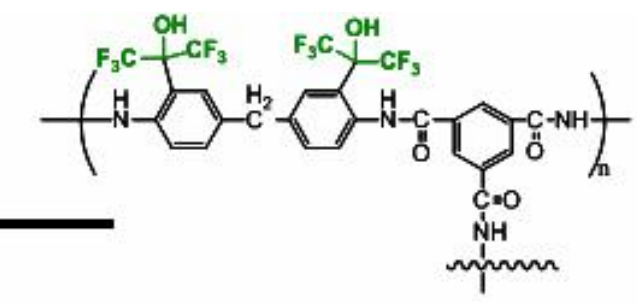

HFA-containing polyamide ( $i$-phobe) barrier layer:

Figure 1. Cross-sectional SEM image of $i$-phobe membrane and the chemical structure of i-phobe barrier layer

POSS and PEGM) was spread on the top surface of the dried PSF support membrane using a Gardco automatic drawdown machine with a coating rod (size: 0 , coating membrane using HFA-substituted aromatic diamine (HFA-MDA) and TMC, dissolved in aqueous basic solution $(\mathrm{NaOH}(\mathrm{aq})$ ) and organic solvent (e.g. 
hexane), respectively. Figure 1 shows cross-sectional SEM image of i-phobe membrane. A thin (ca. $350 \mathrm{~nm}$ ) and dense polyamide layer was successfully formed on porous PSF UF membranes. We found that membrane performance of HFApolyamides was improved when the polymerization was done on the UV-ozone treated polysulfone (PSF) support membranes. This is presumably due to enhanced hydrophilicity of the hydrophobic PSF support membrane. An increased hydrophilic nature of UV-ozone treated PSF allows high coverage of ionized HFA-diamine monomer which is dissoved in aqueous basic solution.

The separation performance of $i$-phobe membranes was evaluated by crossflow filtration system at various pHs. Figure 2 show the salt rejection ( $)$ and water flux (•) of $i$-phobe membranes measured at $\mathrm{pH}$ $4,6,8$, and 10 . Both salt rejection and water flux of the $i$-phobe membrane were strongly dependent on feed water $\mathrm{pH}$. The salt rejection was relatively low at $\mathrm{pH} 4$ (R $=85.0 \%$ ), but it increased to $96.1 \%$ at $\mathrm{pH}$ 10. The water flux at $\mathrm{pH} 10$ (ca. $88 \mathrm{LMH}$ ) was almost double that measured at $\mathrm{pH} 4$ (ca. $48 \mathrm{LMH}$ ). Such a strong $\mathrm{pH}$ dependant behavior of $i$-phobe membrane is due to ionization of HFA functionalities (from $\left(\mathrm{CF}_{3}\right)_{2} \mathrm{OH}$ to $\left(\mathrm{CF}_{3}\right)_{2} \mathrm{O}^{-}$). pKa of HFA is around 10 , so that the i-phobe membranes become more hydrophilic at

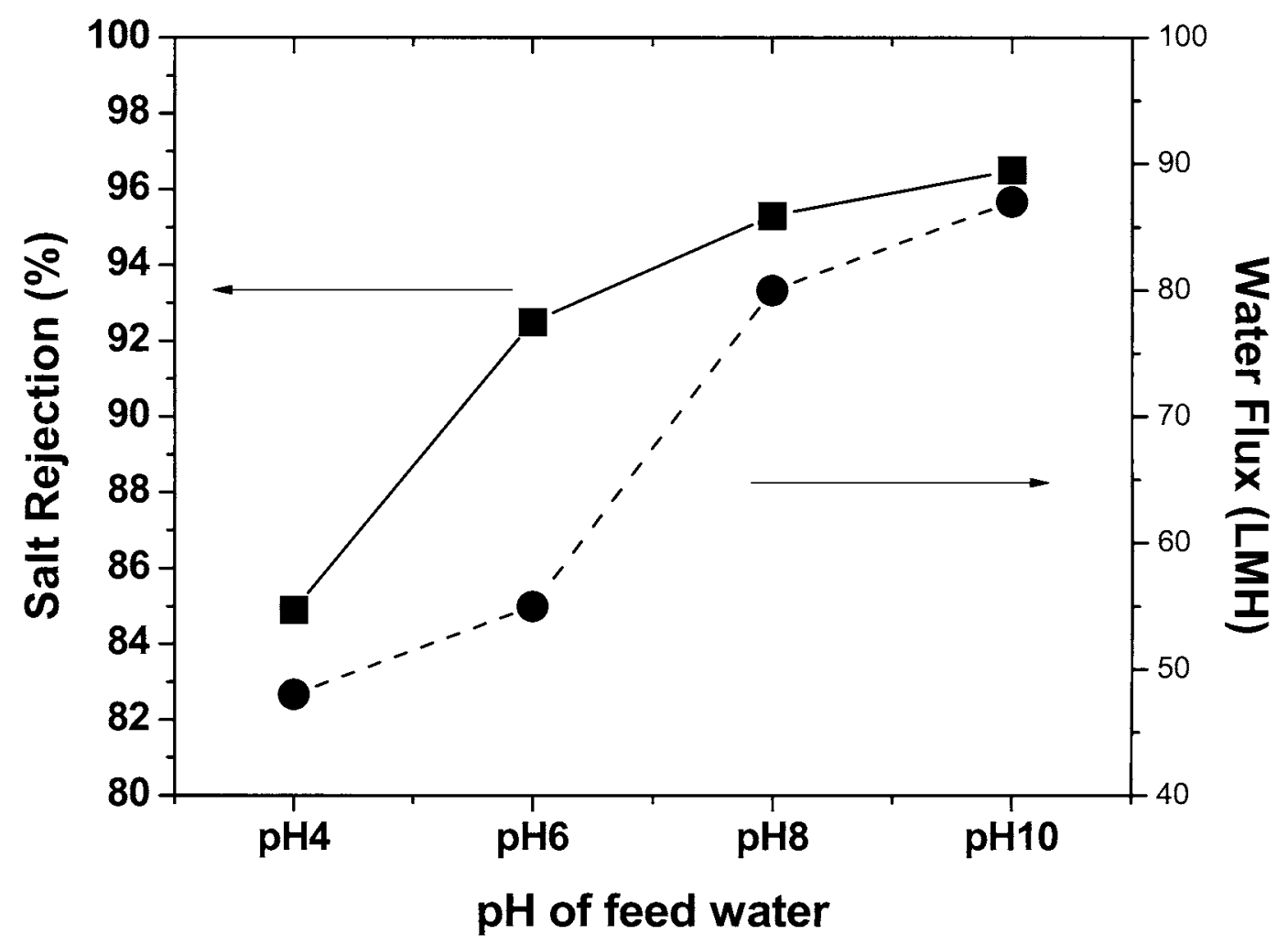

Figure 2. Salt rejection ( $)$ and water flux $(\bullet)\left(\mathrm{LMH}=\mathrm{L} \mathrm{m}^{-2} \mathrm{~h}^{-1}\right)$ values of $i$-phobe membrane. All data were obtained by using cross-flow filtration system with $2000 \mathrm{ppm} \mathrm{NaCl}$ solution at 27.6 bar (cross-flow $3.8 \mathrm{~L} \mathrm{~min}^{-1}$ ). 
basic condition. Enhanced hydrophilicity and charge density of i-phobe membrane at high $\mathrm{pH}$ (ca. 10) contribute to increased water flux and salt rejection (Donnan exclusion), respectively. Ionization behavior HFA functionalites upon $\mathrm{pH}$ control was clearbly verified by contact angle measurement and XPS analysis and described in our previous article [7].

Recently, it has been reported that high $\mathrm{pH}$ operation $(\mathrm{pH} \approx 10$ ) would be advantageous in $\mathrm{RO}$ processes because silica scaling and organic fouling could be minimized at this condition, and besides, toxin residues such as boron and arsenic could be effectively filtered out at basic conditions [3]. Boron and arsenic (specifically arsenite: As(III)) rejection rates normally depend on the $\mathrm{pH}$ of feed water because these compounds are nonionic at neutral conditions and become ionic at basic conditions $(\mathrm{pH} \geq 9.0)$. Figure 3 and Figure 4 show boron and arsenic (As(V) and $\mathrm{As}(\mathrm{III}))$ rejection rates measured with i-phobe membranes at various $\mathrm{pHs}$, respectively. The membrane filtered out more than $80 \%$ of boron from water at neutral $\mathrm{pH}$ and removed almost $97.8 \%$ of boron at $\mathrm{pH} 11.7$, which is superior to the performance of commercial RO membranes.

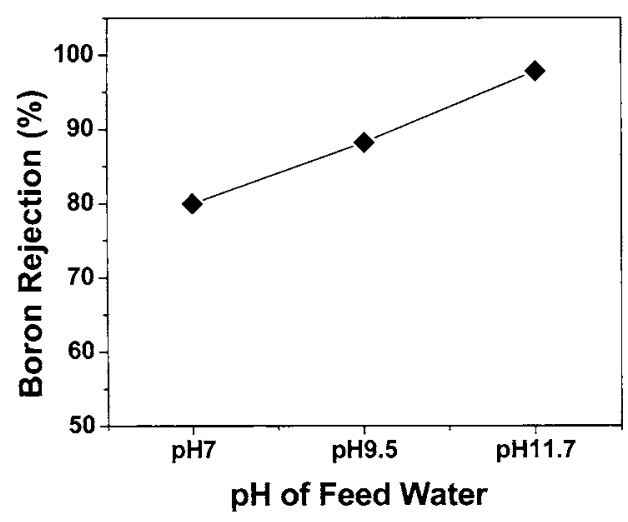

Figure 3. Boron rejection rates of $i$-phobe membranes at various $\mathrm{pHs}$.
The membrane also effectively filtered out predominant arsenic species. $\mathrm{As}(\mathrm{V})$ rejection was very high over broad pH range $(\mathrm{pH} 4 \sim 10)$, while As(III) rejection increased from $51.0 \%$ to $94.5 \%$ by increasing $\mathrm{pH}$ of feed water from 4 to 12. Improved performance of i-phobe membrane in toxin removal (arsenic and boron) at high $\mathrm{pH}$, compared to commercial RO membranes, is likely due to electronic charge repusion between the ionized HFA groups and the ionized toxins.

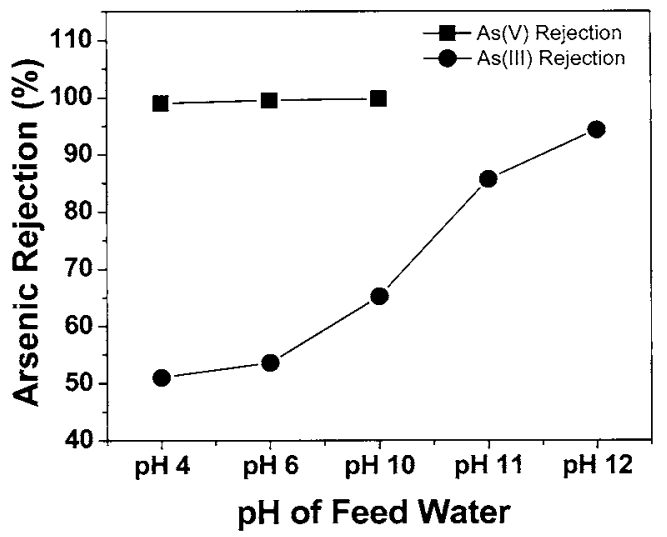

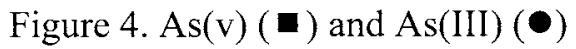
rejection rates of $i$-phobe membranes at various $\mathrm{pHs}$.

Since HFA is an electron withdrawing group and sterically bulky, both the electronic and steric factors could effectively reduce the probability of electrophilic chlorine attack on the benzene ring or the amide group in the polymeric backbone, which is a major problem causing the performance decline in conventional aromatic polyamide membranes. Previous chlorine durability studies using NMR, XPS and desalination performance analyses suggest that the HFA-substituted aromatic polyamide (HFA-PA) is more robust than nonsubstituted aromatic polyamide in the presence of oxidizing agents $(\mathrm{HOCl}$ or 
$\left.\mathrm{OCl}^{-}\right)$[7].

3.2. Anti-fouling coatings based on POSS and PEGM

Polyhedral oligomeric silsesquioxane (POSS) which contains UV-curable functional groups in its 8,10 or 12 vertices (depending on the cage structure) can be used as an excellent building block to form thin and durable polymer films with a functionalized hydrophilic comonomer such a polyethylene glycol methacrylate (PEGM). The water uptake and permeability of photo-crosslinked POSS-PEGM films are easily controlled measuring the weight of dried film $\left(\mathrm{W}_{\mathrm{d}}\right)$ and wet film $\left(\mathrm{W}_{\mathrm{s}}\right)$ through the equation of $\mathrm{S}=\mathrm{W}_{\mathrm{s}}-\mathrm{W}_{\mathrm{d}} / \mathrm{W}_{\mathrm{d}} \times 100$ to characterize the water transport property of the films. The water uptake was increased from $8 \%$ to $120 \%$ as the content of PEGM increases from $30 \%$ to $97 \%$. The water uptake was further improved by adding water soluble sacrificial additives, noncrosslinkable polyethylene glycol (PEG), into the prepolymerization mixture of POSS and PEGM (weight ratio of POSS: PEG-M = 1:20), and extracting out the additives after UV-curing. Highest water

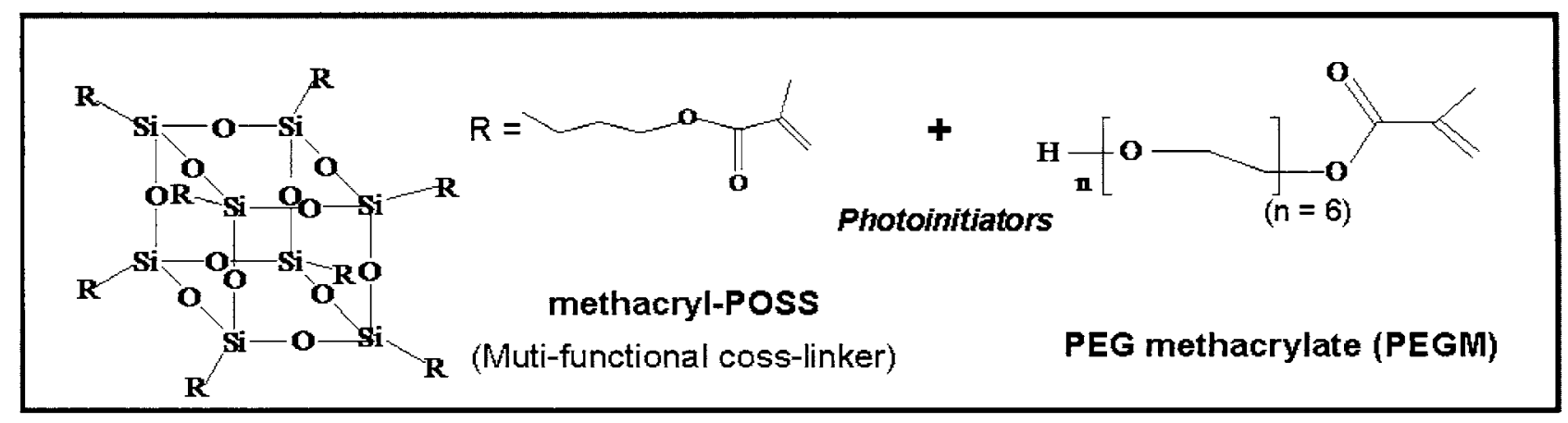

Scheme 1. Reaction scheme.

by manipulating composition ratio between POSS and PEGM. The addition of water-soluble additives into prepolymer mixture of POSS and PEGM, and subsequent extraction of the additives from UV-cured films can generate nanoscale channels and/or pores within the polymer films, resulting in significant increase in water permeability as well as water uptake.

Free-standing films composed of methacryl-POSS and PEGM, have been prepared via UV curing process in the presence of photo-initiator, and the composition between POSS and PEGM were controlled from 1:1 to 1:30 of weight Ratio (see Scheme 1).

Pure water uptake (S) of these free standing films was calculated by uptake $(276 \%)$ was observed at the film prepared with $50 \%(\mathrm{w} / \mathrm{w})$ PEG additive (50\% was maximum amount can be added for possible film-handling) and the film showed high water permeability (133 L $\mu \mathrm{m} \mathrm{m} \mathrm{m}^{-2} \mathrm{~h}^{-1} \mathrm{~atm}^{-1}$ ) as well. Highly water permeable, hydrophilic materials could be promising candidates for anti-fouling coatings to reduce organic or bio fouling in the membrane filtration.

To test anti-fouling efficiency of POSSPEGM materials, the pre-polymer mixtures of methacryl POSS, PEGM and PEG additives including photoinitiator were spread on the top surface of the polysulfone (PSF) ultrafiltration membranes and UV cured. The membranes were then soaked into water to extract water-soluble PEG additives out 
from the films, and the separation performance was evaluated by using crossflow filtration system with synthetic feed waters including target foulants (oils in this study). The water flux of uncoated PSF membrane was significantly lowered within 2 hours, which indicates severe oil fouling. However, POSS-PEGM coated PSF membrane demonstrated good oilfouling resistance, resulting in higher water flux than uncoated membrane over a long period of operating time.

\section{Summary}

This paper presents two examples of water purification materials, both having origins in resist chemistry presented previously at the International Conference of Photopolymer Science and Technology. The first example concerns a reverse osmosis membrane material designed to be fabricated by interfacial polycondensation. The new membrane contains HFA (hexa fluoro alcohol) groups. High $\mathrm{pH}$ operation was found to provide benefit to separation performance, using sodium chloride, arsenic and boron compounds. A nanofiltration membrane was described that was prepared by reactive casting of a photopolymerizable mixture of functional crosslinkers, functional oligomers and free radical photoinitators. The material was found to have good anti-fouling properties.

\section{References}

1. National Geographic, April 2010, Special Issue.

2. R. F. Service, Science, 313 (2006), 1088.; M. A. Shannon, P. W. Bohn, M. Elimelech, J. G. Georgiadis, B. J. Mariñas and A. M. Mayes, Nature, 452 (2008), 301.

3. R. J. Petersen, J. Membr. Sci., 83 (1993), 81.; T. Matsuura, Desalination, J. Membr. Sci., 134 (2001), 27.; N. Vainrot, M. S. Eisen and R. Semiat, MRS Bulletin, 33 (2008), 16.

4. Ju, H.; McCloskey, B. D.; Sagle, A. C.; Wu, Y.-H.; Kusuma, V. A.; Freeman, B. D. J. Membr. Sci., 307 (2008), 260-267.

5. R. Allen, G. Breyta, P. Brock, R. DiPietro, D. Sanders, R. Sooriyakumaran and L. Sundberg, J. Photopolym. Sci. Technol., 19(5), 569-572 (2006).

6. F. A. Houle, D. C. Miller, A. Fornof, H. Truong, S. Raoux, R. Sooriyakumaran, H. Ito and M. Hart, J. Photopolym. Sci Technol, 21, 563-572 (2008).

7. Y.-H. La, R. Sooriyakumaran, D.C. Miller, M. Fujiwara, Y. Terui, K. Yamanaka, B. D. McCloskey, B. D. Freeman, and R. D. Allen, J. Mater.Chem., 2010, DOI: 10.1039/ b925270c. 